\title{
Portugal ante la Guerra Civil Española
}

\author{
Soledad Gómez de las Heras Hernández
}

Desde el 17 de julio de 1936 dos naciones de segundo orden, España y Portugal, van a aparecer como protagonistas en el escenario internacional de Europa para permanecer como constante pesadilla a lo largo de tres años en las relaciones exteriores de las potencias mundiales.

Además de las tensiones que existian entre fascismo y comunismo, el asentamiento de un régimen totalitario en España añadia una nueva causa al desequilibrio europeo. Mientras esta posibilidad era motivo de preocupación para el gobierno del Frente Popular en Francia, obsesionaba a la Unión Soviética, favorecia a Alemania, alegraba a Mussolini y obligaba a Gran Bretaña a afinar al máximo su política apaciguadora, Portugal recibia con alivio la noticia del "alzamiento»; a esta pequeña nación se le brindaba la oportunidad de librarse de esa continua amenaza del otro lado de la frontera que suponia el gobierno republicano al régimen de Salazar. Cuando el levantamiento militar se transformó en guerra civil la política salazarista se orientó hacia los sucesos de la vecina nación, si habia algún pais a quién afectaba directamente el desenlace de la sublevación era a Portugal. Mientras la política interior se proyecta hacia un fortalecimiento de la dictadura, la política exterior se encamina hacia la conservación de la secular amistad con Inglaterra, la defensa de la identidad portuguesa frente al pais vecino, $y$, en caso de conflicto europeo, mantener una postura de neutralidad a la que era necesario arrastrar a España, la España a la que habia que apoyar frente al peligro comunista.

Salazar siempre consideró la República Española fácilmente resbaladiza hacia el comunismo y, aunque en Portugal está firmemente asentado su régimen personalista, cuando estalla el conflicto español, vuelve los ojos hacia su nación y refuerza la dictadura. El Estado Novo necesitaba mantener a distancia cualquier amenaza revolucionaria y utiliza todos los medios a su alcance para mantener el orden social. El mínimo pretexto es utilizado para hacer ver el peligro que supone el comunismo para la nación y dar fundamento a las simpatias por la causa nacionalista. 
Una particular circunstancia favoreció la política interna llevada a cabo por Salazar, claramente encaminada a consolidar su sistema político, durante la Guerra Civil Española: la ausencia de un fuerte grupo de oposición. Aunque no se puede negar que, paralelamente a la división del pueblo español, existe también una radicalización del pueblo portugués en campos ideológicos distintos que se definen y polarizan en función del apoyo o la hostilidad al Estado Novo, estar con los nacionales es estar con Salazar y con los gubernamentales estar en contra 1, la gran masa portuguesa no vislumbra los beneficios de la victoria de uno u otro bando; tiene el deseo de que los acontecimientos de España afecten lo menos posible a sus intereses y, en cierta medida, se inclinan por los nacionales en cuanto que se presentan como defensores de valores tan arraigados en el pueblo lusitano como la familia, el orden, la propiedad, la lglesia Católica.

La oposición está desunida y diseminada, ciertamente hubiera sido un buen momento para aglutinarse ${ }^{2}$ pero los circulos democráticos se dividen al juzgar si la gravedad del momento internacional aconsejaba o no prudencia, encuentran menor apoyo en los gobiernos extranjeros, enzardados la mayoria en sus propios problemas y, por último, algunos de los adversarios del Estado Novo no por eso eran, a la vez, partidarios de las izquierdas y preferian abstenerse de cualquier actividad hostil. En definitiva, todo ello creó una situación favorable a la politica salazarista ante a la Guerra Civil Española con la que no contaron los paises democráticos ${ }^{3}$.

Toman partido por los gubernamentales los adversarios de Salazar, que esperan colaboración y ayuda del gobierno de Madrid y son estusiastas de los nacionales los más conservadores, monárquicos, y la mayor parte de los católicos, en definitiva, los que simpatizan y colaboran con el Estado Novo.

? Hay conatos de levantamientos subversivos y el mismo Salazar sufre un atentado, del que salió ileso, el 4 de julio de 1937. NogueIRA, F., "Salazar». Livraria Civilizacao Editora, 1986, V.III, págs. 108-109 describe el atentado con cierta precisión.

${ }^{3}$ Pueden servir de ejemplo citas tales como las encontradas en el telegrama del Encargado de Negocios de Portugal en Londres, Calheiros, al Secretario General del Ministerio de Negocios Extranjeros, Londres, 22 de julio de 1936: «.. la opinión personal de Wellesley es que Inglaterra no intervendria militarmente en España, cualquiera que fuese la situación en que ese pais se encontrase. El Gobierno Británico no tendría el apoyo de la opinión pública..." o en el telegrama del Ministro de Portugal en Paris al Secretario General del Ministerio de Negocios Extranjeros, Paris 23 de julio de 1936: “....Los acontecimientos de España causan aqui serios recelos.....El Gobierno Francés, especialmente su parte izquierda, ve con simpatia la causa del Gobierno Español, mirando los acontecimientos como la lucha entre democacia parlamentaria y dictadura. Dos aviadores españoles llegados ayer por via aérea pretenden comprar aqui 40 aeroplanos de caza y y bombarderos del ejército francés. Estableciéndose discusión al respecto de tal concesión, habiendo fuertes oposiciones en la opinión pública y en el ejército...". 
Aunque el gobierno portugués no manifiesta claramente su apoyo a los nacionalistas hasta que corta relaciones con el gobierno de Madrid actua, desde el primer momento, como si de hecho estuviese ya en hostilidades con aquel; a todos los efectos sus acciones conducen a un inestimable apoyo al ejército insurrecto tanto en el plano internacional, con maniobras dilatorias en las negociaciones de los acuerdos, como en la ayuda material.

No en pocas ocasiones se ha formulado la pregunta de si existió al otro lado de la frontera participación en la preparación del alzamiento militar español. A parte de que la situación hubiera sido embarazosa para el ejército sublevado si Portugal se hubiese declarado desde el principio país hostil, no se puede ocultar la colaboración oficiosa del gobierno de Salazar a los nacionalistas siendo Portugal la principal base de encuentro de los rebeldes; autoridades civiles y militares andaban abiertamente por Lisboa donde tenian su centro político a través del cual obtenían material de guerra para el ejército sublevado. La libertad de maniobra es manifiesta y se dispuso del territorio portugués como lugar de conspiración donde relevantes personalidades de la derecha española encontraban todo tipo de facilidades otorgadas por parte del Estado Novo, y, aunque esta ayuda se presenta en los medios diplomáticos como un mero gesto de cortesia y de hospitalidad a los emigrados politicos del pais vecino, no tiene nada de extraño que Lisboa conociese la preparación del levantamiento contra la República Española. En el mes de octubre está constituida oficiosamente en Lisboa una Junta de Representación del Estado Español dirigida por Mariano Amoedo, que solo será disuelta cuando es reconocido «de jure» el Estado Español en mayo de $1938^{4}$.

El gobierno de Salazar ofreceria un auxilio de primordial importancia dando facilidades para la adquisición y transporte de material via Portugal. Esta nación no podia aportar armas pero permitió la utilización de su territorio para que otras naciones facilitaran el abastecimiento necesario y fué allí donde tuvo lugar la llegada de los primeros aviones de los que Burgos carecia, tras las diligencias efectuadas antes de estallar la insurreción ${ }^{5}$.

Si los aeropuertos portugueses fueron lugar de escala de los aviones que Hitler enviaba a los nacionales, el suelo lusitano sirvió de paso para traslados de tropas y material y los puertos estuvieron abiertos a los na-

\footnotetext{
${ }^{4}$ MAE, R-1058. Exp. 6.

'Antes de que se descargaran en Lisboa aviones desmontados de origen alemán ya habian sido entregados cuatro aviones Fokker a través de la British Airways de Lisboa. VIÑAS, A., "La Alemania Nazi y el 18 de Julio", págs. 372-373.
} 
vios con abastecimiento bélico ${ }^{6}$. Otro aspecto, también de gran importancia, de la ayuda de facto a los nacionales fueron las facilidades concedidas para las operaciones financieras. Agentes nacionalistas podian adquirir material en fábricas extranjeras a través de industrias portuguesas; igualmente firmas nacionales lusitanas hacian transacciones con el extranjero y luego con los sublevados españoles, directamente o a través del Estado portugués?

Pero mucho más que un refugio de preparación política, un cuartel general para sus actividades, un lugar donde encuentran hospitalidad figuras relevantes del 18 de julio, un camino por donde atraviesa el material de guerra, una actividad doctrinaria en la radio y la prensa, Salazar va a ofrecer a la causa nacionalista toda una máquina diplomática a su servicio; ciertamente, si valioso es el apoyo de Salazar a Franco en el terreno peninsular, su mayor batalla la va llevar a cabo en la escena internacional donde "Portugal defiende la causa nacionalista con el mismo interés que defiende la cuestión nacionalm.

La perspectiva internacional admitia la hipótesis de un conflicto de proporciones mundiales ante el que Portugal seguiria una politica de neutralidad, postura que, si apenas seria viable en caso de que en España se consolidara un régimen de extrema izquierda, tampoco se veria favorecida con una España endeudada con los totalitarismos de derechas pues las consecuencias serian semejantes: aliada de este otro frente tampoco podría mantenerse alejada de la contienda; por eso la diplomacia de Salazar a lo largo de la Guerra Civil Española va dirigida a intentar continuamente neutralizar la influencia nazi en la alianza con Franco. Habia que asegurar en el país vecino, por tanto, un régimen que, ante la batalla en que se viera implicada Europa, quisiera y consiguiera ser neutral. Con esta visión de la situación que se avecinaba, desde el principio Portugal define una actitud que, por la posición geográfica de la que parte, es decisiva para el desenlace del conflicto.

Dentro del contexto de la política exterior salazarista existía una sola atadura, tan secular como su amistad, que era la vinculación con Gran Bretaña. Cuando los dirigentes españoles de ambos bandos intentan conseguir en Europa el apoyo politico, militar y financiero de los paises ideológicamente afines, Lisboa habia ya comenzado tiempo antes las primeras escaramuzas diplomáticas ante el gobierno de Londres. En marzo de

\footnotetext{
${ }^{6}$ Es importante también recordar que cuando no se habia producido la unión entre los ejércitos del norte y del sur, Portugal es un lugar de retaguardia indispensable para hacer posible el éxito del Alzamiento.

'VINAS, A., op. cit., pág. 328
} 
1936 el Ministro de Asuntos Exteriores, Monteiro, en una larga conversación con el Ministro británico pregunta sobre lo que haria el gobierno inglés "cuando las cosas (en España) tomaran mayores proporciones"; Eden se limita a responder que «...esperaba que el gobierno portugués hiciese lo posible por evitar complicaciones...» el problema español «el será una complicación más en Europa" ${ }^{8}$.

Según avanzaba el tiempo se hacía más necesario para el gobierno portugués conocer el talante de Londres ante los oscuros destinos políticos de España y su grado de compromiso en relación a Lisboa; en la noche del 11 de junio es el mismo Oliveira Salazar quién solicita un cambio de puntos de vista con el Embajador Sir Charles Wingfeld «sobre la eventualidad de la implantación en España de cualquier régimen de carácter comunista o extremista... hipótesis que parecia debia interesar también a Inglaterra" "...nunca se obtuvo del gobierno inglés cualquier respuesta a este respecto. Apenas el embajador dice en conversación particular al Secretario General que el gobierno inglés no trabaja sobre esta hipótesis. Acrecentando personalmente que el comunismo en España ciertemente desagradaria al gobierno inglés...” ${ }^{9}$.

Cuando estalla la sublevación Salazar tenía tomada la decisión. Desde el principio, y antes que otros paises, Portugal define una postura de apoyo a los nacionales. Mientras Roma y Berlin conservan aún su actitud de expectativa; Francia se debate entre las simpatias por los gubernamentales y los avisos que recibe de Londres; Rusia no esconde su apoyo a las izquierdas, Portugal decide desde el mismo 19 de julio utilizar sus medios políticos y diplomáticos al servicio de la causa nacionalista.

Una nueva entrevista es sostenida entre los Ministros del gobierno de Lisboa y de Londres; mientras Portugal persiste en su postura de apoyo a los sublevados le es comunicada la intención de Londres de mantenerse al margen del conflicto español. Monteiro muestra su interés por esclarecer la orientación politica de Gran Bretaña en las cuestiones de la Peninsula Ibérica y, por su parte, Eden, igualmente huidizo que en ocasiones anteriores, se limita a recordar la imposibilidad de intervenir en la política interna de otro pais: "...Conferencié con Eden durante hora y media. Conté... el peligro que corriamos en caso de una victoria de los rojos... Me respondió que no podia tomar posición en materia de política interna de otro pais. Deplorable salida. Se ve que el conflicto le desagra-

\footnotetext{
* Telegrama del Ministro de Negocios Extranjeros, Monteiro, al Secretario General del Ministerio. Londres, 21 de Marzo de 1936.

Telegrama del Secretario General del Ministerio de Negocios Extranjeros al Encargado de Negocios de Portugal en Londres. Lisboa, 22 de junio de 1936.
} 
daba por que tan peligrosa consideraba la victoria de unos como de otros y tanto le desagradaban fascistas como comunistas... Por fin acentuó que el parlamento no le permitiría la intervención en la política interna de otros paises...". La nueva oferta del representante británico de no implicarse en el problema español no hizo cambiar la actitud del ministro salazarista: «Portugal -dirá Monteiro- no puede ser mediador ni se puede permitir independencia en los asuntos de España; o se da la victoria al ejército nacional o, con la implantación del comunismo en la peninsula, mi país se vería seriamente amenazado».

Cuando el gobierno francés propone a las potencias europeas una definición común de neutralidad, París y Londres comienzan a buscar con empeño la adhesión del estado portugués. Por su parte, las autoridades de Lisboa optan por un compás de espera: están pendientes de la definición internacional $y$, sobre todo, de la afirmación militar de los nacionalistas.

Tres son los puntos que el gobierno portugués exige aclarar antes de asumir cualquier compromiso internacional: la adhesión de Rusia al tratado de No-Intervención ${ }^{10}$, la garantía por parte de inglaterra de la protección de los intereses portugueses, y la neutralidad de la zona de Tánger ". Respecto al primer apartado, Portugal considera que mientras Rusia ayude a uno de los contendientes españoles, y especialmente por su situación geográfica, no puede sentirse ajeno a la lucha peninsular y sobre todo cuando, dado el carácter que está adquiriendo el conflicto, es previsible que lleve al escenario ibérico a otros paises europeos; la victoria de las izquierdas supondría una amenaza a su integridad territorial, pero también, según el razonamiento salazarista, pondria en peligro el orden internacional, pués la constitución de una federación de repúblicas ibéricas sería el primer paso para el dominio de Europa. El esfuerzo diplomático portugués va dirigido en este caso a presentar el triunfo comunista como un peligro no solo a la independencia de su nación si no también para el equilibrio de las fuerzas europeas, con ello, además, justifica y, sobre todo legitima, su simpatía por el movimiento nacionalista.

\footnotetext{
${ }^{10}$ A su vez Rusia tenía condicionada su adhesión al Tratado de No-Intervención a la de Portugal

${ }^{11}$ La declaración de neutralidad de la zona de Tánger no planteó discusión, de otra manera hubiera sido un nuevo foco de inestabilidad internacional en una zona particularmente estratégica en el Mediterráneo. Esta neutralidad benefició a las fuerzas rebeldes, pues al retirarse la flota gubernamental permitia el avance de las tropas africanas para el continente $y$. desde el punto de vista político, se confirma el poder de Franco en la zona del Marruecos español.
} 
En cuanto al segundo punto, el de la garantía por parte de Inglaterra de la proteción de los intereses portugueses, responde a la dificil duplicidad de la posición portuguesa: es, por un lado, aliado de Gran Bretaña y por otro amigo de la España nacionalista; si la alianza luso-británica significa la seguridad del imperio colonial portugués, la amistad con la España nacional asegura la supervivencia del régimen Salazarista. Los resultados de una simpatia entre los dos países ibéricos eran fácilmente previsibles, pero se hacia necesario asegurar la eficiencia de la alianza inglesa: «....Es enorme lo que nos viene a pedir. Es un sacrificio inmenso... Es natural que el gobierno portugés quiera mantener una política externa de unidad con el Gobierno de Londres. Pero en la hora dificil que atravesamos precisa saber antes de tomar una solución, si el gobierno inglés garantiza que a las veinticuatro horas que se siguieran a un ataque venido de España y dirigido sobre nosotros, o ante una sublevación provocada en el pais por los extremistas españoles, la escuadra inglesa estaria aqui para defender nuestros puertos, el ejército inglés combatiria a nuestro lado, la flota aérea británica repeleria los ataques de que seriamos victimas..." ${ }^{12}$.

Una nueva habilidad política muestra Salazar que, con una gran firmeza en no alterar la politica trazada con respecto a los insurrectos españoles, intenta una intervención británica más decisiva a favor de Franco que consiga contrarrestar la influencia de la Alemania nazi y sobre todo el endeudamiento de la España franquista con los regímenes totalitarios. Estima Salazar que si se efectúa un cambio político en el país vecino y la victoria del partido nacionalista hubiera sido obtenida sólo con la ayuda de alemanes e italianos, obligaría a la nueva España a una alianza con los paises totalitarios que se volveria contra Gran Bretaña: arrastraria a Portugal a la onda nazi-fascista y la nueva ordenación peninsular significaria la pérdida de la costa atlántica y mediterránea. Para evitar estos previsibles peligros, el representante del Gobierno de Lisboa considera que la actitud de Londres no debe ser de enemistad y antipatia hacia el ejército sublevado: «...para no crear en el partido nacionalista un enemigo, basta que su actitud no sea de antipatía para con él en este momento de lucha - si no puede ser de simpatía para los que en España se baten contra el comunismo-. En esta hipótesis la gratitud del ejército

Eł diplomático británico responde con una pregunta: «... Si, con respecto a la seguridad de Portugal, el gobierno inglés diera las garantias pedidas, ¿se adhería este Gobierno al Acuerdo de No Intervención que le he propuesto?... Se examinará el problema -respondió Monteiro-".

Conversación entre Monteiro y el ministro de Asuntos Exteriores de Inglaterra en Lisboa. Lisboa, 7 de agosto de 1936. 
se iría de cierto exclusivamente para los alemanes y para Italia, estos paises que los auxiliasen en el combate..." ${ }^{13}$.

Con esta nueva estrategia politica, Portugal se alza con interlocutor privilegiado ante el Gobierno Británico y asume el papel de las pequeñas potencias como intermediarias de las grandes o como agentes en asuntos que no pueden ser abordados por los grandes paises. Por su parte Inglaterra, interesada en ganar como sea la adhesión de Portugal al Pacto de Neutralidad, recurso a través del cual cree evitar todos los males, reitera los principios de la secular alianza entre ambos paises, pero se reserva el derecho de juzgar las circunstancias en que tendrá que intervenir en defensa de esta nación amiga.

Una vez conocidas la respectivas comunicaciones de los gobiernos de Londres y Paris ${ }^{14}$, Salazar abandona su actitud intransigente y acepta entrar en la órbita de la ficticia política «no intervencionista», su gobierno está dispuesto a aceptar la fórmula de neutralidad como propuesta transitoria. En apariencia puede resultar sorprendente que Portugal acepte las garantias ofrecidas y se acople a la linea de la política externa inglesa y no lo considere como un simple gesto destinado a obtener como fuese su adhesión. No faltan razones: Salazar está jugando fuerte con el tiempo ${ }^{15} \mathrm{y}$, por un lado, es pronto aún para saber con certeza quién será

${ }^{13}$ «...La victoria del partido nacionalista tendrá consecuencias diferentes para Inglaterra, conforme fuera alcanzada con la decisiva ayuda alemana e italiana o sin ella. Si, colocados en una situación en que su victoria dependa del socorro extranjero, los militares se verán forzados a aceptar de Alemania e Italia los elementos de victoria que le son indispensables, natural es que para estos dos paises se inclinen sus simpatías. Inglaterra corre entonces el riesgo de ver contra ella fortalecida la alianza o solidaridad de los paises de autoridad;.... pero España quedará, después de la lucha presente y durante mucho tiempo, en situación de no poder pensar si no en su propia resurrección. El gobierno inglés tendrá delante de si largo tiempo para negociar». Conversación entre Monteiro y Dod. 7 de agosto de 1936.

${ }_{14}$ Idéntica pregunta que a Londres se hace a Paris por medio de Amè-Leroy, representante francés en Lisboa. Lisboa, 7 de agosto de 1936. La contestación de Paris es análoga a la de Londres: anuncia la adhesión de Rusia al tratado y en cuanto a la independencia de Portugal, que no está ligado a Francia por alianzas, se limita a apuntar los derechos comunes a cualquier miembro del organismo de la Sociedad de Naciones «....acentúa que en este momento lo que importa a su gobierno es la adhesión al principio del Acuerdo. Portugal haría después las observaciones que entendiese al texto del proyecto. En todo caso considera de mayor importancia la necesidad de las caracteristicas del acuerdo, por que en este momento las horas valen por años..." Conversación entre Monteiro y Amè-Leroy. Lisboa, 12 de agosto de 1936.

15 "....Confidencialisimo: mi impresión personal es que el Gobierno Británico y la mayor parte de la opinión inglesa desearian la victoria del Gobierno de Madrid por que recelan del nuevo estado fascista en Europa y suponen que la anarquia o el comunismo no se mantendrian en España, acabando por reconstituirse el Gobierno democrático aunque tuviese acentuadas tendencias socialistas». Telegrama del encargado de Negocios de Portugal en Londres, Calheiros, al ministro de Negocios Extranjeros. Londres, 10 de agosto de 1936. 
el vencedor, si el gobierno español o los sublevados; por otro, espera la definición de las potencias y que se delimiten los dos campos enemigos, pues conoce la estrecha relación que existe entre el escenario español y el europeo; además, los pretextos y diálogos están sirviendo para medir continuamente la reacción del gobierno inglés ante la politica portuguesa de adhesión a la causa nacionalista y, por último, no hay que olvidar que desde el primer momento la política expectante de Salazar va encaminada a dar tiempo a los nacionales para la adquisición de material.

El 21 de agosto de 1936 Portugal se une oficialmente al Acuerdo de No-Intervención. El gobierno de Lisboa está dispuesto a abstenerse de cualquier ingerencia directa o indirecta en los asuntos internos de España, pero, como ya es conocido, soslaya algunos casos de la consideración de intromisión ${ }^{16}$. Eran tantas las reservas y condiciones que suponen una suspensión unilateral del acuerdo siempre y cuando este gobierno lo quiera entender. Portugal se protege adoptando una doble política: por un lado se une al juego de las democracias y de hecho guarda las formas ${ }^{17}$, mientras que desmentidos oficiales y alegaciones a las reservas contenidas en el Acuerdo le sirven a Salazar para disculpar su politica nacionalista.

Una nueva preocupación va a dominar la diplomacia portuguesa ante el problema español: cuando los paises firmantes del Tratado de No Intervención aceptan formar parte del Comité Internacional de Control, Salazar recibe la propuesta con grandes desconfianzas, considera que este nuevo organismo supraestatal no sintoniza con el espíritu del Acuerdo, no tiene fundamento juridico $y$, en lo que se muestra más reiterativo, presupone la insuficiencia de cada estado para aplicar su propia legislación y para mantener los compromisos asumidos; cuestiona, en definitiva, la competencia del comité ante la soberania de las naciones y, sobre todo, no está dispuesto a renunciar a las reservas con que accedió a entrar en el tratado de neutralidad.

Con este nuevo motivo, mientras que en todas las reuniones del Comité y Subcomité se hacen oir las protestas por la ausencia de Portugal y las denuncias contra este gobierno por su constante ayuda a los nacio-

${ }^{16}$ Las condiciones de adhesión de Portugal al Acuerdo de No intervención se encuentran en la nota del Ministro de Asuntos Exteriores de Portugal, Monteiro, al embajador Británico en Lisboa. Lisboa, 21 de agosto de 1936.

"Cuando se desplaza el marqués de Quintanar como representante de la Junta de Burgos, el Ministro de Asuntos Exteriores se abstiene de responder a la notificación y de recibir al delegado nacionalista. Sin embargo estaba de delegado secreto del General Franco, su hermano Nicolás con un pasaporte a nombre de Fernández Águila. NogueIrA, F., op. cit., pág. 26. 
nales, tres orientaciones contrapuestas se debaten en el escenario politico europeo: la de Londres, la de Salazar y la de Monteiro, Ministro de Asuntos Exteriores de Portugal. Nuevamente el gobierno inglés hace lo posible por vencer la resistencia de Lisboa e intenta todo tipo de negociaciones para conseguir que las autoridades portuguesas consientan en hacerse representar en Londres. El Embajador británico insiste en el carácter consultivo del Comité ${ }^{18}$, la independencia de sus miembros y las innecesarias sospechas que levanta la actitud de los gobernantes portugueses; Lisboa se reafirma en las razones de la postura adoptada y adelanta la noticia del acercamiento al gobierno de Burgos ${ }^{19}$. El Ministro Monteiro comprende el papel de Londres como fiel de la balanza en el equilibrio europeo, considera que son suficientes las garantias dadas por Londres e intenta evitar que Gran Bretaña juzgue que Portugal estrecha relaciones con Berlin y, en definitiva, ve conveniente no salir de la órbita politica inglesa. Por último, la visión inalterable en politica externa de Salazar, que no acepta llevar representación a Londres hasta que las compentencias del Comité estuviesen claramente definidas. Sabe que un control efectivo perjudicaría a los nacionales y, además, lo considera una claudicación ante la insistencia del gobierno británico.

Desacuerdos y contradicciones entre Salazar y su ministro van a crear un clima de confusión en los medios politicos internacionales: mientras Eden y Monteiro intentan una fórmula bilateral satisfactoria para sus dos paises, que permitiera la presencia portuguesa en el Comité Internacio-

${ }^{18}$ “... pero la comisión no os obliga a nada. Es un simple clearing..."-dice el Embajador Británico- "No es asi. Nos obliga a tratar con paises con quien no queremos trata. Nos obliga a escuchar sus criticas, a sufrir sus acusaciones, a prestar atención posiblemente a sus recomendaciones. Desde que entremos en la Comisión tenemos que considerarnos iguales a los otros miembros. No queremos". Conversación entre el Ministro de Asuntos Exteriores de Portugal y el Embajador Británico en Lisboa. Lisboa, 11 de septiembre de 1936.

${ }^{19}$ La conversación es la siguiente: - «... Vengo a implorar de parte de mi gobierno la adhesión del Gobierno Portugués a la Comisión... Bien. No insisto más en este punto.

Digame vuestra excelencia señor Ministro, hay alguna cosa de nuevo en las relaciones de Portugal con España?

- Voy a dirigirme a la Junta de Burgos a pedir las disculpas y satisfacciones que el Gobierno de Madrid no me dio ahora.

- Pero eso es muy grave.

- Ya hace dias, en la segunda feria pasada, le conté el caso

- Vuestra Excelencia me dijo que podia volverse muy grave, pero no me dijo que se iba a dirigir a la Junta de Burgos.

-Pero no es un reconocimiento oficial?

-Ahora no es un reconocimiento oficial. Pero es, bien claramente, la afirmación de que ellos ejercen la soberania efectiva sobre las regiones de la frontera portuguesa..." Lisboa, 11 de septiembre de 1936. 
nal, Salazar, enfurecido por lo que considera una sumisión humillante ante el gobierno inglés, elabora una nota oficiosa ${ }^{20}$ que sorprende a Monteiro, contraria a Inglaterra y es considerada inadmisible por el gobierno francés. El texto, que contiene y argumenta, aunque de forma poco diplomática, «la filosofia» de Salazar sobre el carácter y el alcance político de la guerra civil española, responsabiliza a los intereses particulares del gobierno francés de la politica no intervencionista en el problema español y, también con una alusión implicita a Francia, destaca el papel del comunismo «entre bastidores» como motor de la transformación política en Europa: “...más valioso para el comunismo ibérico que un cargamento de armas y municiones sería la transformación política operada en Portugal que volviese vulnerable la retaguardia de todo el ejército español... una pregunta indiscreta: también en ese caso interesaría tanto como ahora que nos adhirieramos al compromiso de No-Intervención?...". Con una sarcástica humildad se atribuye Salazar una importancia secundaria en la ayuda a los nacionales; su estilo en este escrito contrasta con la oratoria triunfalista de los discursos que vislumbran la victoria nacionalista, y posteriores a esta, donde concede un valor relevante y transcendental a la colaboración portuguesa: «...no nos podriamos creer que constituimos, pais tan modesto como somos, estorbo mayor en su funcionamiento y en sus decisiones. No solo el acuerdo de No-Intervención y la vigencia del decreto que lo hace cumplir en Portugal son independientes del Comité, si no que en el caso presente, estando en él los paises productores de armamento, estando en el por igual representados los mayores intereses en presencia de cuya actuación nuestra situación de posible pais de tránsito es absolutamente secundaria...».

Por lo demás, esta inoportuna nota oficiosa de Salazar, escrita desde su retiro en su tierra natal y publicada en la prensa al dia siguiente de ser elaborada, es una réplica a las duras críticas difundidas en los circulos políticos, y en gran parte de la opinión pública, internacionales, que creaban una atmósfera de hostilidad contra Portugal por su actitud ante la guerra civil española, y una reacción, no excesivamente deliberada, ante las presiones que ejercia la diplomacia británica, empujada por Francia, sobre su Ministro de Exteriores ${ }^{21}$.

En Ginebra conoce el ministro portugués la impresión que habia causado en el entorno político europeo la nota de Salazar, y, todavia sin co-

\footnotetext{
${ }^{20}$ Nota oficiosa de la Presidencia del Consejo. "Los Acontecimientos de España y la Nointervención». Lisboa, 22 de septiembre de 1936.

"Esta frase es una contestación directa a las palabras de Eden afirmando que: "Portugal tiene en el Comité grandes amigos».
} 
nocer el texto, asegura a Eden la representación de su país e intenta convencer a Salazar de la necesidad de "agradar" a Londres y adaptarse a su política exterior: "sería una prueba de buena voluntad con Inglaterra que tanto insiste en la participación portuguesa - argumenta Monteiro-, el aislamiento internacional sería un obstáculo para el rearmamiento del ejército portugués y sería muy grave un enfrentamiento con Inglaterra sobre todo cuando "es grande el esfuerzo que ciertos países hacen para separarnos de Londres" "... las cosas van a cambiar rápidamente hasta el punto que nos veremos amenazados, y no creo que en este momento eso convenga... Haremos el favor a Londres o de otro modo no haremos el favor a nadie..." además «... las izquierdas utilizan el viejo tema del cambio de apoyo de nuestra política...". Salazar, pertinaz y sin abandonar su obcecación, aisla lo que él considera dos problemas politicos difentes: su fidelidad a Inglaterra, que es indiscutible, y el hecho puntual de la integración en el comité de Londres, es decir, su postura pronacionalista española que afecta a su integridad nacional: «... la cuestión de la adhesión al comité nunca fue puesto como favor a Inglaterra o demostración de nuestra indiscutible fidelidad a ésta. Vuestra Excelencia sabe que todos los favores y servicios prestados a lo solicitado por el señor Eden no tuvieron para nosotros hasta ahora cualquier compensación, como acontece en la cuestión de armamento... la explotación por las izquierdas del viejo asunto del cambio de política tradicional tiende precisamente como dice a hacernos cambiar en la cuestión del Comité. Es consideración para estar vigilantes, pero sin gran preocupación..." ${ }^{22}$.

El 28 de septiembre de 1936 un representante de Portugal asiste a la reunión del Comité de Londres; Salazar habia consentido esta comparecencia aunque aún no se le hubieran comunicado oficialmente las reglas de funcionamiento y las competencias concretas de este organismo supraestatal, pues admite que están aún en fase de discusión. Con una especial preocupación por la opinión pública de su pais para quién -asegura Salazar- «el interés sobre el caso es muy grande», exige el derecho a afirmar en nota oficiosa que las condiciones impuestas por el gobierno portugués el 21 de agosto se mantenian y, al ser respetadas tales reservas, se había permitido que el pais estuviera representado en Londres. Nuevamente se ve Salazar obligado a transigir, forzado, proba-

22 Del Secretario General de Negocios Extranjeros al Delegado Permanente de Portugal junto a la Sociedad de Naciones. Lisboa, 24 de septiembre de 1936. «... Y esta es la consecuencia lógica de lo que decimos y hacemos hasta ahora. Pero debe parecer que cedemos sin eso y solo por que Inglaterra nos lo pide para satisfacer al Gobierno Francés, que es de hecho, como se vé por informaciones de Vuestra Excelencia y del señor Ochoa, quien presionó por motivos de su pólitica interna». 
blemente, por el enorme descontento que habia causado en la diplomacia de Europa la nota oficiosa de 22 de septiembre y el hecho de que Inglaterra considerase que existian sobrados fundamentos para la irritación francesa ${ }^{23}$. La noticia ${ }^{24}$ se entregó a la prensa con una orden para que no resaltase en las páginas de los diarios pués “... la opinión pública que tan calurosamente ha apoyado la actitud del gobierno en esta cuestión, no comprenderia de cara a tal texto nuestra transigencia y quedaria desagradablemente impresionada y desilusionada." La nota del Presidente del Consejo Portugués no hace más que salvar las apariencias pués la entrada de Portugal en el Comité de Control nunca fue bien vista en los circulos cercanos a Salazar; si este admitió de mala gana la participación portuguesa, los medios politicos que le rodean tampoco la aprobaron y en el entorno diplomático se habla de un éxito del Foreing Office y de un fortalecimiento de la política inglesa. Por otro lado, la izquierda portuguesa acusa al gobierno de poner en peligro la alianza inglesa, hostilizar a Francia y aliarse a Alemania e Italia por afinidades ideológicas en contra de los intereses portugueses; los periódicos gubernamentales españoles lo consideran como una cesión ante la presión de Francia e Inglaterra ${ }^{25}$. La prensa oficial de Portugal se esfuerza en hacer ver que no ha existido una ruptura en la tradicional alianza británica ni mucho menos de igualdad ideológica con Alemania e Italia, e insiste en los deseos iberistas de absorción de Portugal alimentados por algunos politicos españoles.

Aunque se ha presentado como una decisión politica de Salazar que «sin poder politico o militar, y apenas con los recursos políticos, resuelve enfrentarse a la Unión Soviética en la Península, intervenir en la alta politica de las grandes potencias europeas, destruir una posición internacional de supuesta neutralidad que favorecia a los gubernamentales so-

${ }^{23}$ De hecho entre los dias 25 y 28 de septiembre la mayor parte de la correspondencia entre Ginebra y Lisboa contiene múltiples explicaciones a Francia e Inglaterra sobre la nota oficiosa de Salazar. En Dez Anos de Politica Externa. Lisboa 1964, V. III, págs. 344-348.

${ }^{24}$ O Seculo, 29 de septiembre de 1936. «... Por su lado, el presidente del Comité comunicó oficialmente en Ginebra al señor Ministro de los Negocios Extranjeros las reglas adoptadas para el funcionamiento de aquel organismo. Juzgó el Gobierno, en cara de tales comunicaciones, poder dar orden a nuestro representante en Londres para tomar parte en las sesiones del Comité. Esta resolución no perjudica en nada las reservas y condiciones con que el Gobierno portugués, por su su nota de 21 de Agosto (1936), se adherió al pacto de No-intervención en España...

23 “El Ministro de los negocios extranjeros de Portugal, Sr. Monteiro, sometiéndose a la presión franco-inglesa, acordó enviar un representante al Comité... se entiende que la decisión portuguesa se debe a la intención del Ministro del Estado español, Sr. del Vayo, de denunciar ante la sociedad de naciones la ayuda portuguesa a los rebeldes", se escribe en El Liberal de 25 de septiembre de 1936. 
lamente, asegurar la victoria de las fuerzas nacionalistas" ${ }^{26}$, la responsabilidad se descargó sobre Monteiro que se convierte en chivo expiatorio de los infortunios de la politica exterior portuguesa ${ }^{27}$ y es cesado de la cartera de Asuntos Exteriores, que es asumida por el mismo Salazar ${ }^{28}$. A la vez, se intenta salvar la "imagen transigente" del Presidente del Consejo acentuando la flaqueza del ministro quien «... perturbado con un ambiente hostil que se encuentra en Ginebra, receloso de las diligencias francesas sobre el bloqueo, obcecado con lo que juzga serán las imposiciones de la alianza inglesa, subyugado por el encanto personal y fascinación ejercidos por Eden, Monteiro transige y cede aceptar la carta del Presidente del Comité, y apenas en la respuesta alude a las reservas y condiciones portuguesas y telegrafía directamente a Londres dando orden a Calheiros para que comparezca en la reunión de la segunda feria". "... Superada la crisis de las conversaciones de Ginebra, y forzado a aceptar la participación en el Comité de Londres por el nerviosismo de Monteiro, Salazar pasa una semana en Santa Comba y ni sale de su aldea, ni recibe a nadie» 29 .

En los medios politicos internacionales no se confió en la adhesión de Salazar, ni éste pensó en ningún momento en abandonar la politica pronacionalista. Salazar se adapta a las nuevas circunstancias de la no-intervención y percibe las ventajas de defender la causa nacionalista dentro de la politica internacional. La estrategia de Portugal en Londres nunca sufrió un desvio hacia el abandono del movimiento de Franco y, en ocasiones, lo puso por delante de la alianza inglesa. Su objetivo sigue siendo contrapesar la ayuda nazi con una influencia decisiva de Londres.

Para la politica internacional la victoria de la diplomacia británica fue efímera. La presencia de Portugal en el Comité no consiguió el equilibrio deseado por Inglatera, es más, acrecentó las tensiones y puso de relieve el antagonismo político que reinaba en Europa. Las siguientes sesiones del Comité, que coinciden con el momento en que la intervención sovié-

\footnotetext{
${ }^{26}$ Nogueira, F., op. cit., págs. 44-45.

"Delgado, I., "Portugal e a Guerra Civil de Espanha", Publicacoes Europa-America, $n$. 162, pág. 58.

28 "El precario el estado de salud de Armando Monteiro, y preveyendo tiempos dificiles Salazar se pregunta si aquél estará en condiciones físicas de enfrentarlos. Para más, después de la indecisión y timidez de Monteiro en Ginebra, la confianza del jefe de Gobierno quedó alterada. Salazar resuelve sustituir al ministro. Piensa en varios nombres. Se fija en Fezas Vidal y le pide que acepte el cargo. Pero Vidal, después de veinticuatro horas de reflexión declina. Sin embargo, de las responsabilidades como jefe de gobierno, y de haber tomado para si la gerencia de las finanzas y de guerra, Salazar decide entonces asumir la carga de los Exteriores". NogufiRA, F., op. cit, pág. 55.

${ }^{29}$ Nogueira, F., op. cit., pág. 43.
} 
tica y la alemana e italiana en España están en auge, son el escenario en el que se formulan constantes recriminaciones entre Rusia ${ }^{30}$ y Portugal ${ }^{31}$. La posición del delegado de Lisboa fue más cómoda pues, mientras la Unión Soviética se encuentra entre las naciones democráticas y las fascistas, las normas del Comite permitieron a Portugal maniobras diplomáticas y, sobre todo, se vio apoyado por las delegaciones de Alemania e Italia. Mientras Londres, que pretende disminuir la tensión y llegar a un consenso, intenta minimizar el alcance de las acusaciones que se lanzan contra Portugal, esta nación es capaz de producir tal viraje que en el foro internacional de acusado se eleva a acusador ${ }^{32}$. En este ambiente de contradicciones quien salió beneficiado fue el pais más pequeño, y con él la causa nacional española, pues, detrás de las acusaciones entrecruzadas existian los verdaderos problemas que habia puesto de relieve la guerra española y el Comité fue incapaz de controlar el agravamiento de la situación.

Una vez que se habia asentado con una cierta seguridad en el marco politico de Europa, Salazar suspende las relaciones diplomáticas con el gobierno de Madrid y se reafirma en la defensa de la causa nacionalista. La situación cada vez más complicada en España y las acusaciones del gobierno de Madrid crearon un malestar creciente entre los dos países ibéricos. Por otra parte, las denuncias de Rusia por las infracciones del acuerdo, llevan al total deterioro y Lisboa, que se presenta como parte ofendida, rompe con el gobierno de Madrid. El 23 de octubre de 1936 el Embajador de España en Lisboa, Sánchez Albornoz, recibe una extensa nota repleta de recriminaciones, en la que Portugal intenta justificar su actitud al tener un compromiso que le obligaba con las potencias firmantes del acuerdo y, sobre todo, al tratarse de un gobierno legalmente establecido. La violación de la frontera portuguesa, la confiscación de la correspondencia diplomática, las vejaciones al cuerpo diplomático, un incidente con un navio de guerra portugués y ahora las acusaciones contra

30 Las acusaciones son muy concretas: Portugal seria una de las principales bases de abastecimiento y operaciones de los rebeldes; Lisboa es un depósito de mercancias y tránsito de material de guerra; la conquista de Badajoz fue facilitada por el lado Portugués.

${ }^{31}$ El Embajador Portugués en Praga, Costa Carneiro, en un telegrama a Salazar, (29 septiembre 1936), dice que Portugal se encuentra "between the devil and deep sea" e indica con esta frase cual puede ser la explicación por la que Portugal ha cedido a participar en la no-intervención.

${ }^{32}$ No se puede acusar al gobierno Portugués de no desear la paz, si admitió la participación en Londres fue para negociaciones pero no para recibir acusaciones de un gobierno a quien no le reconoce la legitimidad a inmiscuirse en los asuntos portugueses. Si reponde a las acusaciones es sólo por el respeto que le merece Inglaterra, dirá el representante de Portugal en el Comité. 
las autoridades portuguesas de no garantizar la total libertad al Embajador de España en Lisboa, son las principales razones que explican que: «en estas circunstancias es imposible al gobierno de Lisboa mantener relaciones diplomáticas normales con el gobierno que vuestra excelencia representa: desde ahora mismo las considero suspendidas" ${ }^{33}$.

Es cierto que el gobierno británico tenia conocimiento de que Salazar estaba dispuesto a dar el paso y no faltaron las diligencias que intentaban disuadir a Lisboa de tal decisión; la única consideración con su pais aliado fue el darle a conocer las intenciones de esta ruptura, que casi desde el principio de la guerra deseaba, antes de hacerlo de forma oficial, pero no deja de ser presentado como un hecho consumado ${ }^{34}$. Lisboa recibe la gratitud de las autoridades de Burgos que conocen el decisivo alcance del apoyo de Portugal. El 18 de noviembre de 1936 Alemania e Italia reconocen al Gobierno de Burgos; si Salazar no sigue el mismo camino es por la presión que Gran Bretaña ejerció constantemente para obtener el respeto a la neutralidad ${ }^{35}$.

Las propuestas de control de los puntos de entradas a España provocan una nueva tensión en el ministerio de exteriores portugués y vuelven a poner de manifiesto un antiguo contenciosos; Portugal aludiendo nuevamente a la razón de su soberanía y la autonomia de cada estado en el cumplimiento de los compromisos internacionales, se niega a que sus puertos y fronteras sean controlados ${ }^{36}$, parece que el gobierno de Salazar, en ese dilema de siempre entre la conveniencia politica y el deseo de servir a la causa franquista, estaba dispuesto a romper con el gobierno de Su Majestad para evitar subordinarse a los dictámenes de la politica europea ${ }^{37}$. Por otra parte, la política a seguir por los países fascistas tampoco está muy definida y, a veces, se muestra contradictoria; si por un lado conviene impedir la ayuda rusa y la entrada de voluntarios,

${ }^{33}$ Comunicado al Embajador de España, Sánchez Albornoz, de la ruptura de las relaciones diplomáticas entre Portugal y España. AMAE de Lisboa, Proc. n. ${ }^{\circ}$ 28/1.

34 Delgado, I., op. cit, pág, 75, comenta que es "a pesar de un posible enfrentamiento con la politica inglesa". Es probable que no supusiese tal enfrentamiento en cuanto a la ruptura, aunque posiblemente si existiese en cuanto al momento de hacerlo que a Londres le pareciese precipitado.

${ }^{3}$ Delgado, I., op. cit., pág. 61, considera que "a pesar del reconocimiento oficial del gobierno de Burgos por parte de Alemania y de Italia en noviembre de 1936 y de la presión sobre el gobierno portugués para seguir el mismo camino, Salazar se abstiene de dar ese paso, que podria, eventualmente, estorbar la libertad de acción en Londres".

${ }^{36}$ Ver los documentos publicados en Dez Anos de Politica Externa, op cit., pág. 586 y 588. 634.

${ }^{3}$ Ver los documentos publicados en Dez Anos de Politica Externa, op. cit., pág. 625 y 
por otro los recursos de material del ejército nacional estaban incompletos. Italia y Alemania necesitan adherirse a las propuestas de control pero con propuestas complicadas y dilatorias que permitieran la llegada de material al ejército de Franco. En enero de 1937, cuando estos efectivos alcanzaban notables proporciones, Portugal adopta una postura de paralelismo a la actuación nazi-fascista y el papel de la delegación portuguesa se reduce al apoyo a estos paises dentro de la linea de obstruccion al control.

A partir de febrero del mismo año Londres vuelve a insistir en la fiscalización internacional ${ }^{38}$; tras un breve tiempo en que se mantiene una postura de resistencia, se produce un inesperado viraje de la política portuguesa y Salazar acepta el proyecto ${ }^{39}$. Sin olvidar la posibilidad de que el estadista portugués midiera las consecuencias de un aislacionismo, también es cierto que se vio demasiado comprometido dentro de la línea de las presiones y garantías del bloque Roma-Berlín y volvió otra vez a las relaciones bilaterales con Londres. Por parte del gobierno inglés se acepta este viraje: dentro del panorama europeo Rusia resulta peligrosa a los intereses británicos y además, Inglaterra deseaba empezar a entenderse con los nacionalistas, posibles vencedores. La fórmula salazarista por la que se invita al gobierno británico a nombrar observadores en las fronteras luso-españolas y a fiscalizar el cumplimiento riguroso por parte de Portugal del Acuerdo de No-intervención, es aceptada por Londres. EI 2 de marzo de 1937 Eden lo anuncia en los Comunes y elogia la actitud del gobierno portugués por haber propuesto soluciones que se fundaban en la antigua amistad existente entre los dos paises; mientras en Francia se comenta «el sabotaje sistemático que dura desde hace meses y que se ejerce en interés del bando nacionalista, Portugal toma posiciones que ni Alemania ni Italia podrian mantener abiertamente», Portugal se relega a un cómodo segundo plano. La situación internacional aún más agravada, la definición militar de las fuerzas que luchan en España y el impacto que en la opinión mundial tienen los hechos que ponen de manifiesto el grado de compromiso de las fuerzas que intervienen en la peninsula, aconsejan la subordinación de los intereses portugueses a los acuerdos con Inglaterra y se cierra la fase del protagonismo de Portugal.

A partir del verano del 37 existe un paréntesis en la politica exterior de Londres durante el cual la fiscalización terrestre y marítima quedan

${ }^{38}$ Ver los documentos publicados en Dez Anos de Politica Externa, op. cit, pág. 645.

${ }^{39}$ Nuevamente se entrecruzan opiniones discrepantes sobre la conveniencia de adhesión a este proyecto entre Monteiro, que se encuentra como embajador en Londres, y Salazar. Ver Delgado, I., op. cit., págs. 130-148. 
aletargados. En el otoño, cuando es previsible que el desenlace de la guerra sea a favor del General Franco, y mientras en el Comité se debate la fiscalización, la retirada de los voluntarios, incómodos ya para los dos bandos, y el reconocimiento del derecho de beligerancia, Inglaterra vuelve a ocupar su posición de mediadora entre las fuerzas contrapuestas. Ante la nueva reorganización de la política internacional, presidida por el interés de Europa en la aceleración de la guerra española, las autoridades portuguesas consideran que ha llegado el momento de enviar un representante al gobierno de Burgos —diciembre de 1937-, proceso de aproximación que se verá reforzado por el reconocimiento oficial en mayo de 1938.

Ya en el verano de 1938 el motor del desequilibrio es la crisis europea y no la guerra civil española. Franco, que se encontraba dentro de unas coordenadas internacionales cada vez más comprometidas, ante la posibilidad de un conflicto europeo ve amenazada su frontera de los Pirineos y el Marruecos español y gira hacia una politica de buenas relaciones con Inglaterra y un distanciamiento de Alemania e Italia. Ahora, era necesario asegurar que no venia ningún peligro por la frontera con Portugal. Esta nación estaba ligada a Inglaterra, ya había reconocido al gobierno nacional, era palpable la ayuda recibida y Salazar era doctrinalmente cercano a Franco, sólo faltaba concretar la postura en caso de un conflicto bélico en el viejo continente. Un tratado de No-Agresión, dando seguridades al gobierno portugués para tratar libremente con Inglaterra, alejaría todo recelo por parte de Portugal y a España le aseguraria no tener la amenaza de ningún peligro procedente de esa frontera. La aceleración de los sucesos en el escenario europeo obligaron a la mutuas declaraciones de neutralidad, lo que benefició un mayor acercamiento de los dos paises ibéricos. Una mayor unión entre Portugal y España, el acercamiento hacia Francia e Inglaterra, la separación aparente de Italia y de Alemania y el gran interés de las potencias europeas para que finalizara la contienda española, fueron las nuevas bases sobre las que se sustentaron las relaciones entre la España Nacional y Europa durante los últimos meses de la guerra civil y el telón de fondo ante el cual se firmaba, el 17 de marzo de 1937, el Pacto de No-Agresión entre Portugal y España, la España que Salazar habia ayudado a triunfar ${ }^{40}$ : «En todos los dominios en que era libre nuestra acción, ayudamos en lo que pudimos al nacionalismo español ...enfrentados por todas partes a la incomprensión y a la ceguera de Europa, donde la España nacional tan pocas amistades contaba, fuimos desde la primera hora lo que debimos ser: amigos fieles de

${ }^{40}$ Gomez de las Heras, M. S., Historia 16, n. ${ }^{\circ} 130$, págs. 11-18. 
España, en el fondo, peninsulares. Perdimos vidas, corrimos riesgos, compartimos sufrimientos, y no tenemos cuentas que presentar. Vencimos, es todo" ${ }^{41}$.

Pocos meses después de concluirse la Guerra Civil Española comenzaba la Segunda Guerra Mundial; la unión politica de los dos paises ibéricos hace de la península una nueva entidad que se separa de Europa, $y$, además, esta postura unitariamente neutral de los gobiernos de Franco y Salazar, no prevista por los paises que iban a combatir en territorio europeo, exhibe como especialmente estrátegico al espacio ibérico y será decisiva para el desenlace del conflicto que se avecinaba.

4. Discurso de Salazar ante la Asamblea Nacional el 22 de mayo de 1939. 